\title{
Learning curve for unilateral endoscopic totally extraperitoneal inguinal hernioplasty in a teaching hospital
}

\author{
(1) Birol Ağca, (1) Yalın İşcan \\ Department of General Surgery, University of Health Sciences, Fatih Sultan Mehmet Training and Research Hospital, İstanbul, Turkey
}

\begin{abstract}
Introduction: The present study is a description of the learning curve experienced and the process implemented to incorporate the increasingly common laparoendoscopic technique of totally extraperitoneal (TEP) inguinal hernia repair at our clinic.

Materials and Methods: Patients with a primary unilateral inguinal hernia who underwent laparoscopic TEP repair between May 2013 and May 2018 were included in the study. The patients were separated into 7 groups. The learning curve parameters (duration of operation, rate of conversion to open surgery, intraoperative and postoperative complications) were recorded and statistically compared.

Results: Of the 380 patients, 349 were male and 31 were female, and the mean age was $52 \pm 14.2$ years. The mean duration of the operation was $46 \pm 25.9$ minutes. There was a statistically significant difference between the groups in terms of surgical time. The duration of the operation plateaued at $<1$ hour after 60 surgeries. There was no statistically significant difference between the last 2 groups in terms of the duration of the operation. A total of 7 patients were converted to open surgery. There was no difference between groups in terms of the duration of hospitalization. The average follow-up period was 18 months (range: 3-63 months). Seroma and hematoma occurred in 3 patients and hernia recurrence was observed in 4 patients.

Conclusion: It was concluded that a surgeon who has already performed a certain number of inguinal hernia operations can complete the learning curve for TEP repair after 60 operations when the appropriate technical conditions are provided, and that subsequent surgeries can be performed in an optimal time with low complication and recurrence rates.
\end{abstract}

Keywords: Duration of surgery; laparoendoscopic repair; learning curve; totally extraperitoneal.

\section{Introduction}

Inguinal hernia repair is performed every year in more than 20 million people worldwide. ${ }^{[1]}$ These surgeries are performed with open or laparo-endoscopic technique and the primary priority is to reduce the recurrence and compli- cation rates. Laparoscopic inguinal hernia repair (LIHR) is currently not widely accepted among surgeons. ${ }^{[2]}$ Most surgeons prefer to pursue their knowledge and skills gained in the first years of education in this regard. ${ }^{[3]}$ Undoubt- 
edly the greatest help in developing and implementing techniques is guidelines. The first comprehensive guide prepared for inguinal surgery is published by European Hernia Society (EHS) in 2009.[4] According to "International Guidelines for Groin Hernia Management”, which is the most current guide, inguinal hernia repair has been simplified from hundreds of techniques that were used, to only open mesh technique (Lichtenstein) and laparo-endoscopic mesh techniques [totally extraperitoneal technique (TEP) and transabdominal preperitoneal technique (TAPP) ] are recommended..$^{[5]}$

Since there is no generally accepted technique for inguinal hernia repair, it has also been reported that surgeons should offer both anterior (Lichtenstein) and posterior (TEP or TAPP) approaches for treatment. ${ }^{[6]}$ In literature, laparo-endoscopic repair applied in primary unilateral inguinal hernia, especially in male patients, is advised for alleviation of the post-operative acute pain and the chronic pain that may occur later, even though the evidence level is low. ${ }^{[3,5]}$ Laparoscopic TEP repair has become increasingly popular from 1992 onwards, up to the present. Less pain, more rapid return to work and better cosmetic results, especially in bilateral hernia, are the greatest advantages of this technique. ${ }^{[7]}$ However, the limitation of the operative field in laparoscopic TEP repair leads to both an increase in the duration of the operation and a higher rate of complication during the learning curve. ${ }^{[8]}$ In literature, it has been reported that between 20 and 400 surgeries are required to be performed for learning curve of laparoscopic TEP repair. ${ }^{[9]}$ The main reason why this method is not preferred at the desired level is the difficulty of the learning curve. ${ }^{[10]}$

The present study aims to determine the learning curve of the laparoscopic TEP technique applied in our clinic, the estimated number of operations to be performed from the beginning to the optimal level, and to discuss it in the context of the current literature.

\section{Materials and Methods}

Patients with a primary unilateral inguinal hernia who underwent elective surgery between the dates of May 2013 and May 2018 were included in the study. Patient records were retrospectively scanned with the help of a computer database. Patients with scrotal hernia, patients that underwent lower abdominal surgery, patients with recurrent or bilateral hernia, The American Society of Anesthesiologists (ASA) IV patients were excluded from the study. Ap- proval for study was obtained from the local ethics committee for hospital data use. Written informed consent was obtained from all patients included in the study. The surgeons performing the surgery were experienced surgeons who have performed a certain number of open inguinal hernia surgery and laparoscopic surgery. The patients were divided into seven groups. The first four groups consisted of 20 patients and the last three groups consisted of 100 patients per group, with a total of 380 patients. Age, sex, hernia side, ASA scores, duration of hospitalization and complications were recorded in the groups. Duration of surgery was statistically compared between the groups. Learning curve evaluation parameters were; duration of operation, rate of conversion to open surgery, intraoperative and postoperative complications.The duration of surgery was recorded as the time from the first cut to the skin closure. Routine outpatient clinic follow-ups were performed at the $1^{\text {st }}$ week and $3^{\text {rd }}$ months after the operation. Patients who could not come to the outpatient clinic follow-ups were reached by telephone. Hematoma, seroma formation and wound infections were recorded. Seroma was defined clinically and radiologically as fluid presence on the surgical site or scrotum.

\section{Surgical Technique}

After the patient was sterilized in the trendelenburg position under general anesthesia, the anterior rectus fascia was reached by passing the layers with semicircular incision made from under the umbilicus in the region corresponding to the hernia side. Skin and subcutaneous tissues were retracted with s shaped retractor. Anterior rectus sheath was fully revealed. After the incision was made on the anterior rectus sheath, the rectus muscle was laterally slanted, a balloon trocar was inserted, and the operative field was created without damaging the posterior sheath. The operative field was then visualized with carbon dioxide insufflation at $14 \mathrm{~mm} \mathrm{Hg}$. Two $5 \mathrm{~mm}$ trocars were placed between the umbilicus and the symphysis pubis. Blunt dissection was performed under the view of the 300 telescope until the symphysis pubis was clearly visible. Inferior epigastric vessels were clearly visualized laterally on the posterior surface of the rectus muscle. The retropubic space of Retzius and the space of Bogros were expanded. Hernia defect was identified. In cases with medially located direct inguinal hernia, laterally located indirect inguinal hernia, or combined inguinal hernia, dissection of the peritoneal sac off the cord structures was performed. After dissecting all potential hernia areas and lowering the hernia sheath, 
Table 1. Demographic characteristic and type of hernias, by patient group

\begin{tabular}{|c|c|c|c|c|c|c|c|c|}
\hline Characteristic & $\begin{array}{l}\text { Group I } \\
(n=20)\end{array}$ & $\begin{array}{c}\text { Group II } \\
(n=20)\end{array}$ & $\begin{array}{c}\text { Group III } \\
(n=20)\end{array}$ & $\begin{array}{c}\text { Group IV } \\
(n=20)\end{array}$ & $\begin{array}{l}\text { Group V } \\
(n=100)\end{array}$ & $\begin{array}{l}\text { Group VI } \\
(n=100)\end{array}$ & $\begin{array}{l}\text { Group VII } \\
(n=100)\end{array}$ & $p *$ \\
\hline Mean age, years & 51.11 & 57.75 & 59.3 & 54.45 & 51.25 & 52.04 & 51.21 & 0.07 \\
\hline Male/female & 19/1 & $20 / 0$ & $17 / 3$ & $18 / 2$ & $91 / 9$ & $94 / 6$ & $90 / 10$ & 0.09 \\
\hline Left/right & $15 / 5$ & $14 / 6$ & $16 / 4$ & $11 / 9$ & $55 / 45$ & $68 / 32$ & $42 / 58$ & 0.30 \\
\hline \multicolumn{9}{|l|}{ Hernia type, no. } \\
\hline Indirect & 18 & 19 & 17 & 15 & 73 & 81 & 74 & \\
\hline Direct & 2 & 1 & 3 & 4 & 23 & 11 & 24 & \\
\hline Femoral & 0 & 0 & 0 & 1 & 1 & 1 & 0 & \\
\hline Complex & 0 & 0 & 0 & 0 & 3 & 7 & 2 & \\
\hline
\end{tabular}

Kruskal Wallis Test. * $\mathrm{P}<0.05$.

the $4 \mathrm{D}$ mesh (Biotech Cousine) at $17 \mathrm{x} 17 \mathrm{~cm}$ was spread and fixed to cover the myopectineal orifice. After complete desufflation with continuous visual control of the operative field, the trocars were removed. A facial suture was applied for the subumbilical incision. Skin incisions were appropriately closed.

\section{Postoperative Evaluation}

Patients were allowed to continue normal diet and normal activity after surgery. All patients received oral propoxifene $50 \mathrm{mg} /$ day and $325 \mathrm{mg}$ paracetamol 4 times/day. The duration of hospitalization was recorded as the total number of nights spent at the hospital after the operation. The patients were seen in the hernia policlinic by the surgeon performing the operation 1 week after discharge.

\section{Statistical Analyses}

IBM SPSS Statistics 22 (IBM SPSS, Turkey) program was used for statistical analysis while assessing the results obtained in this study. In the assessment of data, suitability of the parameters for normal distribution were evaluated by the Shapiro Wilk test. In the assessment of data, apart from descriptive statistical methods (mean, standard deviation, frequency), Kruskal Wallis test was used in the comparison of quantitative data for comparison of parameters that don't fit to non-normal distribution between groups, and Mann Whitney U test was used to determine the group that caused the difference. The significance was evaluated at $\mathrm{p}<0.05$ level.

\section{Results}

A total of 380 laparoscopic TEP repairs were performed in
$349(92 \%)$ men and $31(8 \%)$ women in the study. Patients were divided into 7 groups, 20 patients per group were included in groups I to IV and 100 patients per group were included in groups V to VII. The follow-up period was 18 (3-63) months. The mean age of the patients was 52.3 (SD 14.2). 159 (42\%) patients had inguinal hernia on their right side, 221 (58\%) patients had inguinal hernia on their left side. According to types of hernia; 297 were indirect, 68 were direct, 3 were femoral, and 12 were complex type. ASA scores of the patients were ASA I 137 (36.05\%), ASA II $162(42.63 \%)$ and ASA III 81 (21.31\%), respectively. The mean duration of operation was 46.1 (SD 25.9) minutes. Table 1 shows the demographic characteristics and hernia types of the patients in the groups. There was statistically significant difference between the first five groups in terms of the duration of operation values $(p<0.05)$. There was no significant difference between the last two groups

Table 2. Comparison of mean duration of surgery in each group

\begin{tabular}{lcc} 
Groups & & Duration of surgery, minute \\
\cline { 3 - 3 } & n & Mean \pm SD \\
\hline Group I & 20 & $119.25 \pm 14.17$ \\
Group II & 20 & $104.25 \pm 10.04$ \\
Group III & 20 & $76.5 \pm 14.52$ \\
Group IV & 20 & $48.5 \pm 9.33$ \\
Group V & 100 & $40.40 \pm 4.96$ \\
Group VI & 100 & $33.35 \pm 5.18$ \\
Group VII & 100 & $33.35 \pm 4.38$ \\
p & & $0.000 *$ \\
\hline Kruskal Wallis Test $* \mathrm{p}<0.05$. &
\end{tabular}


( $p>0.05)$. The mean duration of surgery value was reduced to less than 1 hour after 60 operations and reached a plateau value (Table 2, Fig. 1). A total of 7 patients (3 patients in Groups I and II and 1 patient in Group IV) were converted to open surgery. This was due to peritoneal injury for five patients and due to epigastric vascular injury for two patients. In 12 patients, pneumoperitoneum developed due to partial peritoneal rupture. Five of these patients were converted to open surgery, the procedure was completed in the cases of other patients. The overall mean length of stay in hospital was 1,2 (SD 0.38) days, and the mean length of stay when individual groups were considered was close to 1 day except for group I, which was closer to 2 days (Fig. 2). There was no statistically significant difference between groups in terms of duration of hospitalization ( $p>0.05)$. In the follow-up period, seroma and hematoma developed in three patients, and recur-

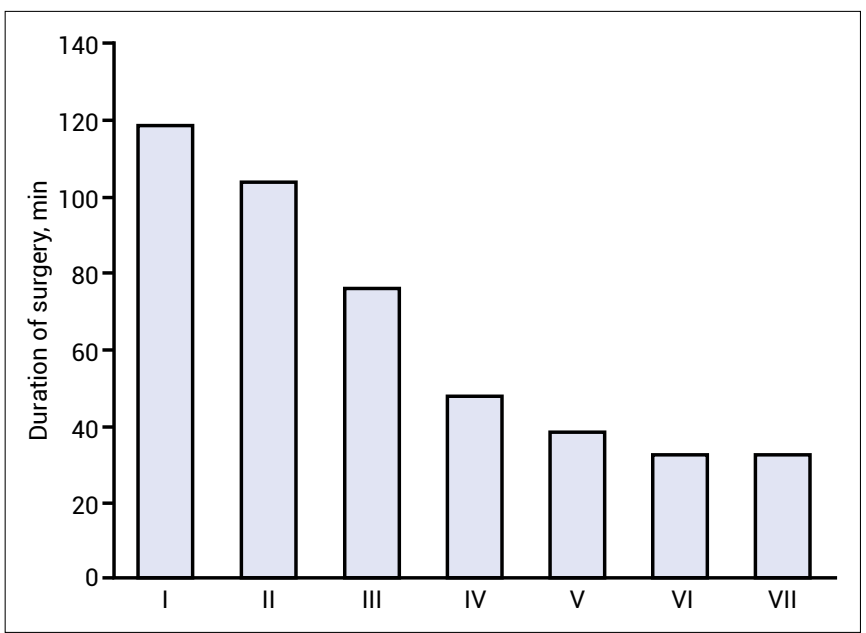

Figure 1. Comparision of mean duration of surgery in each group.

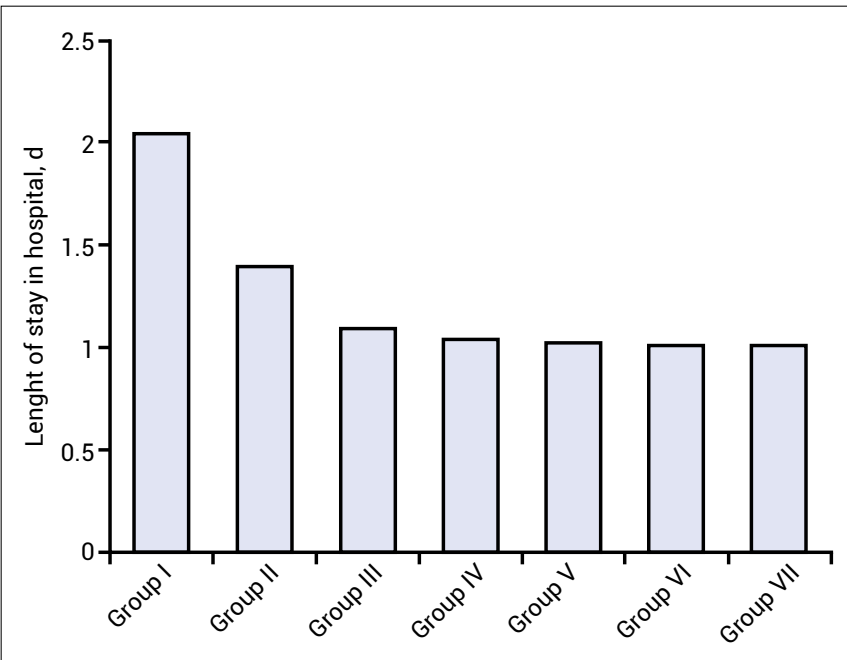

Figure 2. Comparision of mean length of stay in hospital in each group.
Table 3. Incidence of perioperative and postoperative complications

\begin{tabular}{|c|c|c|c|c|}
\hline \multirow[t]{2}{*}{ Complications } & \multicolumn{2}{|c|}{$\begin{array}{c}\text { First } \\
60 \text { cases }\end{array}$} & \multicolumn{2}{|c|}{$\begin{array}{l}\text { Last } \\
320 \text { cases }\end{array}$} \\
\hline & $\mathbf{n}$ & $\%$ & $\mathbf{n}$ & $\%$ \\
\hline Peritoneal injury & 7 & 11.6 & 5 & 1.6 \\
\hline Bleeding & 2 & 3.3 & 0 & 0 \\
\hline Vascular injury & 2 & 3.3 & 0 & 0 \\
\hline Cord injury & 0 & 0 & 0 & 0 \\
\hline Bladder injury & 0 & 0 & 0 & 0 \\
\hline Conversion & 6 & 10 & 1 & 0.3 \\
\hline $\begin{array}{l}\text { Postoperatif } \\
\text { seroma-hematom }\end{array}$ & 2 & 3.3 & 1 & 0.3 \\
\hline Recurrence & 3 & 5 & 1 & 0.3 \\
\hline
\end{tabular}

rence was detected in four patients (Table 3). Seroma and hematoma were treated with aspiration and local debridement. 2 of the recurrences were in group I, 1 was in group II, and 1 in group IV. Lichtenstein repair was performed in patients with recurrent disease.

\section{Discussion}

In recent studies, LIHR has been reported to be more effective and safe due to less pain, rapid return to work and better cosmetic results compared with open repair. ${ }^{[11-13]}$ Although the rates of recurrence in laparoscopic and open mesh repair are similar, recurrence rates are low and patient satisfaction is higher in laparoscopic repairs performed by experienced surgeons. ${ }^{[14]}$ In this method, limited operative field requires special anatomical knowledge for dissection and manipulations to spread the mesh. ${ }^{[15]}$ This has led to less adoption of the technique among surgeons than other minimally invasive techniques. ${ }^{[16]}$ The learning curve in laparoscopic hernia repair was defined as the number of operations needed to stabilize the duration of the operation and the rates of complication. ${ }^{[17]}$ Our study showed that the mean duration of operation of unilateral TEPs reached a plateau of $<1$ hour after 60 procedures. In later operations, the duration was even shorter. Similar findings were reported by Choi et al. ${ }^{[16]}$ as after 60 operations, and by Lau et al. ${ }^{[18]}$ as after 80 operations, the duration was stabilized. Aeberhard et al. ${ }^{[19]}$ showed a significant relationship between the duration of operation and the experience of operator. Different numbers of operation were reported for the learning curve for the TEP method. In the last published international hernia guide, 
discussing about the learning curve for laparoscopic TEP, it was reported that more than 100 repairs on average were required to achieve results comparable to open repair. ${ }^{[5]}$ In the Cochrane review, at least 30 to 100 operations have been suggested to be an experienced surgeon. ${ }^{[20,21]}$ Surgeons who believe in the advantages of laparoscopic repair have developed several methods aiming to complete the learning curve more quickly. Miserez et al. ${ }^{[2]}$ suggested a standardized clinical training program that comprise 10 different consecutive steps for laparoscopic TEP repair. 5 of these steps are basic steps, other 5 are advanced steps, and it is reported that the learning curve can be reduced to 30 operations by this method. Hasbahceci et al. ${ }^{[7]}$ described a two-stage learning curve in TEP repair. They reported the minimum number of operations to be performed without conversion to open surgery for the recognition of the pelvic anatomy at the first stage were 20. They reported that, the surgeon who had technical experience may be able to perform operations with less than $1 \%$ recurrence rates at a later stage.

The main goal of the learning curve is to reduce complications and recurrence rates. In many studies, the major complication rate of TEP is around 1\%. ${ }^{[23,24]}$ Vascular injuries and deep mesh infections are rare. ${ }^{[25]}$ No major vascular injuries were observed in our study. Peritoneal injury is the most important surgical complication in laparoscopic TEP repair. ${ }^{[26]}$ In our study, peritoneal injury developed in $3.2 \%$ of the patients. In this case, which limits the operative field, depending on the size of the injury area, either operation was converted to open surgery or the operation was completed by reducing excess gas pressure from the abdomen by placing a veress needle in the abdomen to reduce the pneumoperitoneum. Peritoneal tearing was more common during the dissection of the indirect hernia sac from spermatic cord. In our study, seven patients were converted to open surgery and Lichtenstein method was applied. Six of these patients were in group 1 and 2, the other one patient was in group 4. Reason for conversion to open surgery was peritoneal injury in 5 patients, and epigastric vascular injuries in 2 patients. Recurrence developed during follow-up in 4 of our patients. Lichtenstein hernioplasty was performed on patients with recurrence.

\section{Conclusions}

In laparoscopic CAP repair, it is difficult to identify the stabilization point of the complications and duration of the surgery to indicate the precise learning curve.Our re- sults were obtained from a single training hospital and the experience of two surgeons. Although it is difficult to generalize for this reason, the number of patients needed for learning curve of unilateral laparoscopic TEP repair is considered to be 60 .

\section{Disclosures}

Ethichs Committee Approval: The study was approved by the Local Ethics Committee.

Peer-review: Externally peer-reviewed.

Conflict of Interest: None declared.

\section{References}

1. Suguita FY, Essu FF, Oliveira LT, luamoto LR, Kato JM, Torsani $M B$, et al. Learning curve takes 65 repetitions of totally extraperitoneal laparoscopy on inguinal hernias for reduction of operating time and complications. Surg Endosc 2017;31:3939-45. [CrossRef]

2. Trevisonno M, Kaneva P, Watanabe $Y$, Fried GM, Feldman LS, Lebedeva $E$, et al. A survey of general surgeons regarding laparoscopic inguinal hernia repair: practice patterns, barriers, and educational needs. Hernia 2015;19:719-24. [CrossRef]

3. Kulaçoğlu H. Comments on the new groin hernia guidelines: What has changed? What has remained unanswered? Turk J Surg 2018;34:83-8. [CrossRef]

4. Simons MP, Aufenacker T, Bay-Nielsen M, Bouillot JL, Campanelli G, Conze J, et al. European Hernia Society guidelines on the treatment of inguinal hernia in adult patients. Hernia 2009;13:343-403. [CrossRef]

5. HerniaSurge Group. International guidelines for groin hernia management. Hernia 2018;22:1-165. [CrossRef]

6. Köckerling F, Simons MP. Current Concepts of Inguinal Hernia Repair. Visc Med 2018;34:145-50. [CrossRef]

7. Hasbahceci M, Basak F, Acar A, Alimoglu O. A New Proposal for Learning Curve of TEP Inguinal Hernia Repair: Ability to Complete Operation Endoscopically as a First Phase of Learning Curve. Minim Invasive Surg 2014;2014:528517.

8. Cavazzola LT, Rosen MJ. Laparoscopic versus open inguinal hernia repair. Surg Clin North Am 2013;93:1269-79. [CrossRef]

9. Mathur S, Lin SY. The learning curve for laparoscopic inguinal hernia repair: a newly qualified surgeon perspective. J Surg Res 2016;205:246-51. [CrossRef]

10. McCormack K, Wake B, Perez J, Fraser C, Cook J, McIntosh $E$, et al. Laparoscopic surgery for inguinal hernia repair: systematic review of effectiveness and economic evaluation. Health Technol Assess 2005;9:1-203. [CrossRef]

11. McCormack K, Scott NW, Go PM, Ross S, Grant AM; EU Hernia Trialists Collaboration. Laparoscopic techniques versus open techniques for inguinal hernia repair. Cochrane Database Syst Rev 2003;CD001785.

12. EU Hernia Trialists Collaboration. Laparoscopic compared 
with open methods of groin hernia repair: systematic review of randomized controlled trials. Br J Surg 2000;87:860-7.

13. Langeveld HR, van't Riet M, Weidema WF, Stassen LP, Steyerberg EW, Lange $\mathrm{J}$, et al. Total extraperitoneal inguinal hernia repair compared with Lichtenstein (the LEVEL-Trial): a randomized controlled trial. Ann Surg 2010;251:819-24. [CrossRef]

14. Eker HH, Langeveld HR, Klitsie PJ, van't Riet M, Stassen LP, Weidema WF, et al. Randomized clinical trial of total extraperitoneal inguinal hernioplasty vs Lichtenstein repair: a long-term follow-up study. Arch Surg 2012;147:256-60.

15. Edwards CC 2nd, Bailey RW. Laparoscopic hernia repair: the learning curve. Surg Laparosc Endosc Percutan Tech 2000;10:149-53. [CrossRef]

16. Choi YY, Kim Z, Hur KY. Learning curve for laparoscopic totally extraperitoneal repair of inguinal hernia. Can J Surg 2012;55:33-6. [CrossRef]

17. Voitk AJ. The learning curve in laparoscopic inguinal hernia repair for the community general surgeon. Can J Surg 1998;41:446-50.

18. Lau H, Patil NG, Yuen WK, Lee F. Learning curve for unilateral endoscopic totally extraperitoneal (TEP) inguinal hernioplasty. Surg Endosc 2002;16:1724-8. [CrossRef]

19. Aeberhard P, Klaiber C, Meyenberg A, Osterwalder A, Tschudi J. Prospective audit of laparoscopic totally extraperitoneal inguinal hernia repair: a multicenter study of the Swiss Association for Laparoscopic and Thoracoscopic Surgery (SALTC). Surg Endosc 1999;13:1115-20. [CrossRef]
20. Schouten N, Simmermacher RK, van Dalen T, Smakman N, Clevers GJ, Davids $\mathrm{PH}$, et al. Is there an end of the "learning curve" of endoscopic totally extraperitoneal (TEP) hernia repair? Surg Endosc 2013;27:789-94. [CrossRef]

21. Wake BL, McCormack K, Fraser C, Vale L, Perez J, Grant AM. Transabdominal pre-peritoneal (TAPP) vs totally extraperitoneal (TEP) laparoscopic techniques for inguinal hernia repair. Cochrane Database Syst Rev 2005:CD004703. [CrossRef]

22. Miserez $M$, Arregui $M$, Bisgaard $T$, Huyghe $M$, Van Bruwaene $\mathrm{S}$, Peeters $\mathrm{E}$, et al. A standardized resident training program in endoscopic surgery in general and in laparoscopic totally extraperitoneal (TEP) inguinal hernia repair in particular. Surg Laparosc Endosc Percutan Tech 2009;19:125-9. [CrossRef]

23. MacFadyen BV Jr, Arregui ME, Corbitt JD Jr, Filipi CJ, Fitzgibbons RJ Jr, Franklin ME, et al. Complications of laparoscopic herniorrhaphy. Surg Endosc 1993;7:155-8. [CrossRef]

24. Phillips EH, Arregui M, Carroll BJ, Corbitt J, Crafton WB, Fallas $\mathrm{MJ}$, et al. Incidence of complications following laparoscopic hernioplasty. Surg Endosc 1995;9:16-21. [CrossRef]

25. McCormack K, Wake BL, Fraser C, Vale L, Perez J, Grant A. Transabdominal pre-peritoneal (TAPP) versus totally extraperitoneal (TEP) laparoscopic techniques for inguinal hernia repair: a systematic review. Hernia 2005;9:109-14.

26. Liem MS, van Steensel CJ, Boelhouwer RU, Weidema WF, Clevers GJ, Meijer WS, et al. The learning curve for totally extraperitoneal laparoscopic inguinal hernia repair. Am J Surg 1996;171:281-5. [CrossRef] 